\title{
PENGENALAN OBJEK WISATA ALAM DI KABUPATEN SELUMA PROVINSI BENGKULU DENGAN MENGGUNAKAN KARAKTER 3D ADOBE PREMIERE DAN BLENDER
}

\author{
Agusdi Syafrizal $^{1}$, Yetman Erwadi ${ }^{2}$, Yuan Ramadh Enddika ${ }^{3}$ \\ ${ }^{1,3}$ Prodi Teknik Informatika Fakultas Teknik Universitas Muhammadiyah Bengkulu \\ ${ }^{2}$ Prodi Sistem Informasi Fakultas Teknik Universitas Muhammadiyah Bengkulu \\ Jl. Bali Kota Bengkulu, telp (0736) 22765/fax (0736) 26161 \\ ${ }^{1}$ agusdisyafrizaleumb.ac.id \\ ${ }^{2}$ yetman@umb. ac.id \\ ${ }^{3}$ yuanramadhenddika@gmail.com
}

\begin{abstract}
Abstrak: Kabupaten Seluma yang terletak di sebelah selatan Provinsi Bengkulu memiliki objek wisatanya yaitu wisata Air Terjun Kroya,Air Terjun Curug Endap,Air Terjun Batu Bekinyau, Air terjun Air Melancar, Cagar Budaya Padang Periangan, , Suban Lubuk Resam, Sungai Lubuh Gadis, Susur Goa Resam, Bendungan Seluma, Pantai Muara Kungkai, Pantai Pasar Talo, Pantai Muara Maras, Pantai Ketapang baru, Taman Buru Nasional Semindang Bukit Kabu, tempat wisata ini sangatlah menarik tetapi karena tidak adanya media promosi yang menarik sehingga angka kunjungan wisata baik dalam maupun mancanegara yang berkunjung kesana sangatlah sedikit, seharusnya potensi wisata ini bisa meemberi income bagi daerah. Dengan penggunaan penggunaan teknologi 3D berbasis multimedia sangat efektif memberikan peluang berinteraksi baik secara sinkron (real time) maupun asinkron (delayed), Teknologi 3D suatu objek dapat dilihat dari berbagai arah bukan hanya sekedar gambar yang hanya dapat dilihat dari 2 arah sehingga gambar yang dihasilkan lebih menarik, dengan sentuan teknologi ini memungkinkan gambar tempat wisata bisa dielaborasi dengan .animasi dapat ditampilkan lebih menarik dibandingkan media konvensional seperti televise dan media cetak. Hasil pengujian : Pengguna dapat menambah sendiri fitur-fitur animasi yang dibutuhkan dengan memberi efe-efek untuk membuat gambar lebih menarik., Kelemahan dari dari penggunaan Adobe Premiere adalah kebutuhan spesifikasi komputer yang lebih tinggi atau high-end
\end{abstract}

Kata Kunci: objek wisata, animas 3D, teknologi

Abstract: : Seluma Regency, which is located in the southern part of Bengkulu Province, has its tourist attractions, namely Kroya Waterfall, Curug Endap Waterfall, Batu Bekinyau Waterfall, Melancar Waterfall, Padang Periangan Cultural Heritage, Suban Lubuk Resam, Lubuh Gadis River, Susur Goa Resam, Seluma Dam, Muara Kungkai Beach, Pasar Talo Beach, Muara Maras Beach, Ketapang Baru Beach, Semindang Bukit Kabu National Hunting Park, these tourist attractions are very interesting but due to the absence of attractive promotional media, the number of tourist visits both domestic and foreign visiting there is very little, this tourism potential should be able to provide income for the region. With the use of multimedia-based 3D technology, it is very effective in providing opportunities to interact both synchronously (real time) and asynchronously (delayed), 3D technology of an object can be seen from various directions, not just an image that can only be seen from 2 directions so that the resulting image is more interesting, with a touch of this technology allows pictures of tourist attractions to be elaborated with animation can be displayed more attractive than conventional media such as television and print media. Test results: Users can add animation features themselves needed by giving effects to make the image more attractive. The 
Jurnal Pseudocode, Volume VII Nomor 2, September 2020, ISSN 2355-5920, e-ISSN 2655-1845 www.ejournal.unib.ac.id/index.php/pseudocode

downside of using Adobe Premiere is the need for higher or high-end computer specifications.

Keywords: natural tourism, animation 3D, technology

\section{PENDAHULUAN}

Pemerintahaan Presiden Joko Widodo telah menetapkan Peraturan Presiden Nomor 131 Tahun 2015 tentang penetapan daerah tertinggal tahun 2015-2019, Perpres tersebut, menetapkan 122 Kabupaten sebagai Daerah tertinggal , yang dimaksud dengan daaerah tertinggal adalah daerah kabupaten yang masyarakatnya dan wilayahnya kurang berkembang dibandingkan dengan daerahdaerah lain yang diukur dengan skala nasional, ada 6 (enam) Kriteria utama yaitu yaitu ekonomi, sumber daya manusia, infrastruktur, kapasitas keuangan daerah, aksesibilitas dan karakteristik daerah. Daftar 122 kabuapten yang ditetapkan sebagai daerah tertinggal merupakan bagian dari tertinggal tahun 2014-2019 teridiri dari 138 kabupaten.dan dalam perkembangannya ada 70 kabuapten ditambah 9 (Sembilan) kabuapaten yang mendapat status otonomi daerah baru yang lepas startus dari dari tertinggala yang sebelumnya terdiri dari 138 kabupaten, dari kabupaten tertinggal itu salah satunya adalah kaputen seluma yang merupakan daerah pemekaran dari kabupaten Bengkulu Selatan Provinsi Bengkulu.

Kabupaten Seluma secara geografis terletak di Pantai Barat Pulau Sumatera bagia Selatan, terletak garis bujur dan lintangnya berada pada koordinat $04^{\circ} 21^{\prime} 40^{\prime} 22^{\prime \prime} \quad 03^{\circ} 49^{\prime} 55^{\prime} 66^{\prime \prime}$ Lintang Selatan-Lintang Selatan dan 102'59'40'54', $101^{\circ} 17^{\prime} 27^{\prime} 57^{\prime}$ 'Barat Tenggara- Barat Tenggara (Muntahanah, 2018). Kabupaten ini yang terletak di sebelah selatan Provinsi Bengkulu memiliki objek wisata yang tidak diketahui atau dikunjungi oleh parawisata,adapun wisatanya yaitu wisata Air
Terjun Kroya,Air Terjun Curug Endap,Air Terjun Batu Bekinyau, Air terjun Air Melancar, Cagar Budaya Padang Periangan, , Suban Lubuk Resam, Sungai Lubuh Gadis, Susur Goa Resam, Bendungan Seluma, Pantai Muara Kungkai, Pantai Pasar Talo, Pantai Muara Maras, Pantai Ketapang baru, Taman Buru Nasional Semindang Bukit Kabu. Banyaknya tempat wisata yang menarik tidak ditunjang dengan promosi yang baik sehingga tidak banyak dikenal orang, sehingga potensi untuk pengembangan parawisata tidaklah maksimal dan berdampak kepada pemasukan pemerintah daerah dari sektor pariwisata sangat minim karena sedikit sekali pelancong baik dalam negeri ataupun manca negara yang berkunjung kesana, dank arena kurangnya pemasukan dari sektor berakibat pada terhambatnya pembangunan prasaran penunjang seperti sarana dan fasilitas yang memadai untuk menunjang mobilitas dari pencanangan parawisata sebagai salah income pemasukan daerah disamping sektor yang lainnya.

Televisi merupakan media informasi yang mampu menyajikan tayangan baik secara langsung atau rekaman yang mempunyai kemampuan yang terbatas dan mempunyai banyak kelemahan dibandingkan media yang lain seperti aplikasi promosi berbasi multimedia memberi peluang untuk sinkron (realtime)/secara langsung ataupun asinkron (delayed) atau berupa siaran ulang yang memungkinkan untuk menampilkan tayangan dibanyak tempat dalam waktu bersamaan [1].

Teknik dalam pemisahaan warna overlay, greenscreen dan bluescreen dengan cara pencampuran dua atau lebih pada bingkai phot secara bersamaan, di mana warna (berbagai warna) di hapus (Transfaran) dengan mengganti 
Jurnal Pseudocode, Volume VII Nomor 2, September 2020, ISSN 2355-5920, e-ISSN 2655-1845 www.ejournal.unib.ac.id/index.php/pseudocode

latar belakangnya dengan yang lain adalah kunci dari penggurnaan Chroma Key [2].

Perkembangan animasi sudah menjalar diberbagai sektor, baik industri, perdagangan, bisnis hiburan atau bidang profesi seperti arsitektur, kedoktoran, teknik sipil dan banyak bidang yang lainnya telah menjadi bagian dari kreatifitas [3].

Penelitian ini ditujuhkan untuk merancang dan mengembangkansektor parawisat yang ada di Kabupaten Seluma disajikan asecara nyata (real time) dan dibuat secara menarik untuk penyampai informasi dengan memanfaatkan teknologi multimedia

\section{LANDASAN TEORI}

\section{A. Gambar 3 D}

Suatu objek yang gambarnya bisa dilihat dari semua arah bukan hanya dari depan dan samping saja (gambar 2 D) disebut teknologi 3 D[4]. Penyajian kombinasi (gabungan ) dari berbagai elemen informasi berupa video, teks, grafik yang dilengkapi dengan gambar animasi bertujuaan penyampaian informasi dan hiburan merupakan difinisi dari Multimedia[5]. 3D (tiga dimensi) : yaitu visualisasi sebuah benda atau objek menjadi lebih jelas (mengikuti bentuk aslinya) dan dapat dimengerti dengan baik. [6]. Objek 3D merupakan suatu manipulasi objek yang memiliki panjang, lebar dan tinggi atau menggunakan 3 sumbu kordinat yaitu $\mathrm{x}, \mathrm{y}$ dan z. objek 3D tampak begitu nyata dikarenakan dia dibuat dari hal yang nyata dan objek 3D ini marak digemari semua kalangan, dikarenakan effect yang tajam dan resolusi warna yang tinggi membuat tampilan 3D jadi lebih nyata dan indah [7].

\section{B. Croma Key}

Penggunaan warna hijau adalah salah satu teknik yang meniru mata manusia yang sangat sensitive dengan warna hijau dimana warna hijau memilki noise yang paling kecil sehingga warna hijau merupakan warna terbersih dari warna yang lain, hal ini menjadikan Chrome Key menggunakan sensor gambar pada video digital menggunakan warna hijau [8]. Sejarah teknik penggabungan dua gambar menjadi satu di dunia film diawali oleh Frank Williams, yang menggunakan proses black-backing matting, yang ia patenkan pada 1918 [9]

\section{Video}

Berbagai macam penggunaan video yaitu video analog dan video digital, dimana video analog dibentuk dari deretan sinyal elektrik (gelombang analog) direkam dengan menggunakan kamera dan disebarluaskan melalui gelombang suara dimana terdapat gambar bergerak yang saling berurutan satu sama lainnya [10].. Video adalah rekaman gambar yang berisi mengenai rancangan asas-asas usaha baik dalam menyampaikan pesan atau kata kesan yangditayangkan kembali melaluimedia layar Televisi [11]. Video merupakan media audio visual yang sudah beredar di masyarakat dan banyak diminati oleh anak-anak sekolah dasar, mulai dari jenis video hiburan, pengetahuan, informasi, musik, dan cerita-cerita bersejarah bisa disaksikan dengan mudah.[12].

\section{Animasi}

Perpindahan objek secara riil dan rotasi objek animasi pada ruang 3D adalah difinisi dari Animasi 3D [13]. Pengertian Animasi Animasi merupakan suatu seni untuk membuat dan 
Jurnal Pseudocode, Volume VII Nomor 2, September 2020, ISSN 2355-5920, e-ISSN 2655-1845 www.ejournal.unib.ac.id/index.php/pseudocode

menggerakkan sebuah objek, baik berbentuk 2 dimensi maupun 3 dimensi dan dibuat menggunakan berbagai cara, misalnya menggunakan kertas, komputer dan lain sebagainya. Animasi saat ini telah menjadi industri besar yang memberikan dampak ekonomi dan sosial yang begitu besar bahkan cukup signifikan terhadap pendapat sebuah negara.[14].

\section{E. Editing}

Editing adalah suatu proses memilih, mengatur serta menyusun shot-shot menjadi satu scene, menyusun dan mengatur scene-scene menjadi sequence yang akhirnya merupakan rangkaian shot-shot yang bertutur tentang sebuah cerita utuh.[15]

\section{F. Storyboard}

"Storyboard secara sederhana dapat diartikan sebagai papan cerita. Dalam pengertian yang lebih luas, storyboard merupakan rangkaian gambar sketsa yang merepresentasikan alur sebuah cerita[16]. Papan cerita (storyboard) adlah sebagai media yang merupakan reproduksi bentuk asli dalam dimensi, yang berupa foto atau lukisan[17]

\section{G. Blender}

Blender merupakan software open source yang tidak membutuhkan lisensi dalam penggunaannya dimana dilengkapi fitur seperti modeling, texturing, lighting, animating dan video post processing yang popular digunakan di penjuru dunia [18]. Penggunaan Adobe Photoshop Adobe Premiere dan After Effect digunakan secara luas dalam pengeditan video karena kemudahan sehingga gambar-gambar dibuat dengan efek khusus [19].

Pengembangan Blender berlanjut oleh Ton Roseendal dan tim diseluruh dunia serta relawan pembimbing. Pada tahun 2005, project orange diluncurkan oleh Blender Foundation. Menciptakan dunia film terbuka pertama yaitu Elephants Dream yang menggunakan software Blender 3D sebagai alat utama dibandingkan software open source lainnya [20].

\section{Metode Penelitian}

a. Tempat

Pelaksanaan penelitian dilakuakan di Kabupaten Seluma (Dinas Kebudayaan dan Parawisata ) Jln. Merdeka No 13 talang Saling Kecamatan Seluma Kota.

b. Teknik pengumpulan Data

Data diambil dengan menggunakan tiga instrument yaitu observasi dengan melihat objekobjek wisata yang ada, wawancara dengan instansi yang bersangkutan dan mencari rujukan peneltian sebelumnya (Studi Literature).

c. Metode Pengembangan Sistem

Tahapan dalam pengembangan sistem ini terdiri dari 6 (enam) tahapa yaitu, concept, design, materizal collecting, assembly, testing dan distribution [21].

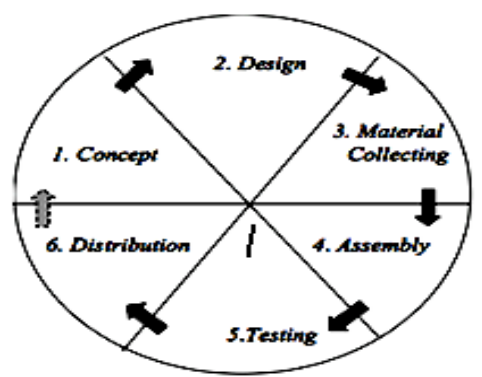

Gambar 1. Metode Sistem Multimedia Luther-Sutopo Tahapannya sebagai berikut :

\section{Concept}

Konsep dalam pembuatan video profile ini adalah menggabungkan karakter 3D di dalam 
Jurnal Pseudocode, Volume VII Nomor 2, September 2020, ISSN 2355-5920, e-ISSN 2655-1845 www.ejournal.unib.ac.id/index.php/pseudocode

sebuah video real untuk menciptakan suatu video yang lebih menarik.Video diawali dengan penjelasan singkat tentang Kabupaten Seluma dengan menampilkan klip-klip video yang telah diedit.Di video ini terdapat 2 karakter 3D,karakter 3D akan menjelaskan tentang seputaran Objek wisata seluma, seperti tempat objek wisata, jarak tempuh dan keunikan objek wisata. Video real dari Objek Wisata Seluma ditampilkan di saatkarakter 3D menjelaskan tentang seputaran Objek Wisata. Video ini akan diakhiri dengan kalimat ajakan dan promosi dari karakter untuk berkunjung ke Kabupaten Seluma.

\section{Design}

Design dalam video profil ini peneliti menggunakan storyboard, dan flowchart untuk mendesain alur video terstruktur dan detail sehingga mempermudah di tahap selanjutnya yaitu assembly (perakitan).

\section{a. Flowchart}

Bentuk flowchart daripembuatan video profil yang akan dibuat adalah sebagaiberikut:

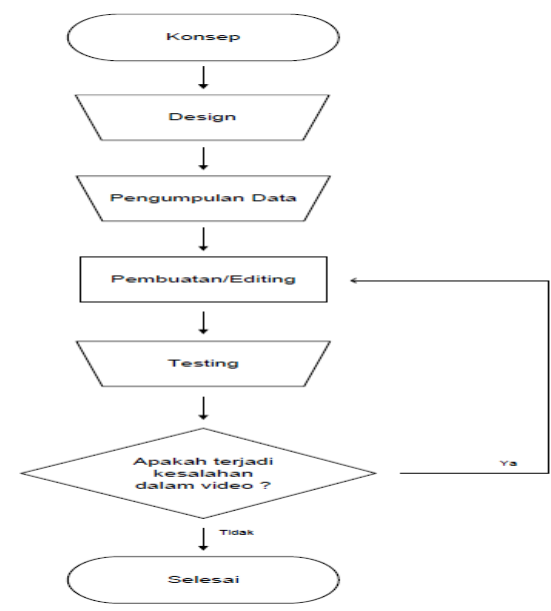

Gambar 2. Flow chart Pembuatan Video Objek Wisata Seluma

\section{b. Storyboard}

Pembuatan storyboard untuk mereflikasikan dalam penyesuaian alur dari cerita dalam penyajian sebagai sketsa atau gambaran dari cerita yang akan dibuat yang beruapa teks, animasi dan suara dalam satu scen

Tabel 1. Storyboard Video Objek Wisata Seluma

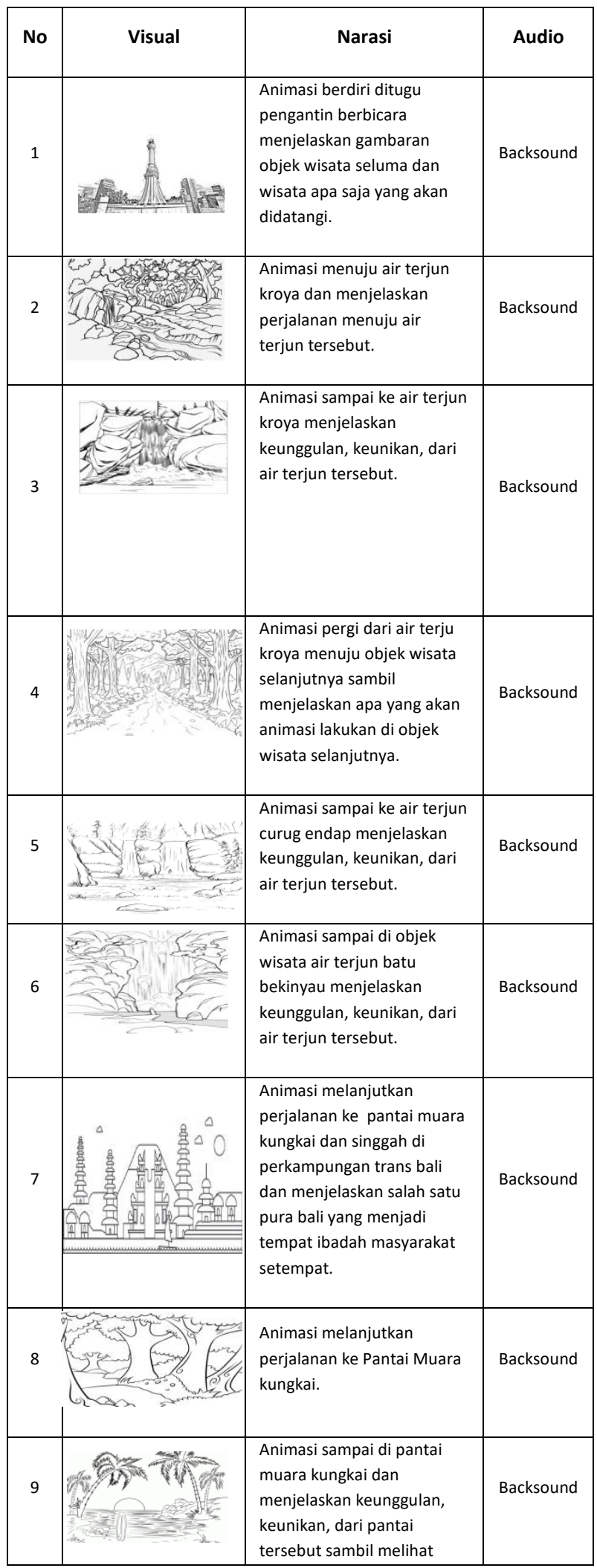


Jurnal Pseudocode, Volume VII Nomor 2, September 2020, ISSN 2355-5920, e-ISSN 2655-1845 www.ejournal.unib.ac.id/index.php/pseudocode

\begin{tabular}{|l|l|l|l}
\hline & & keindahan sekitar pantai. & \\
\hline 10 & $\frac{3}{3}$ & & \\
& & $\begin{array}{l}\text { Ending dari video animasi } \\
\text { mengambil kesimpulan dari } \\
\text { objek wisata yang di } \\
\text { datangi. }\end{array}$ & Backsound \\
& &
\end{tabular}

\section{Material Collecting}

Tahapan pengumpulan bahan yang sesuai denga kebutuhan sistem untuk pengerjaaan selanjutnya.

\section{Assembly}

Tahapan pembuatan dan perangkaian semua objek dari proses sebelumnya yang meruapakan implmenatasi dari storyboard dan diagram alir berdasarjan design yang ada.

\section{Testing}

Tahapan ini merupakan kelanjutan dari tahapan sebelumnya untuk menguji aplikasi yang telah dibuat sebelum digunakan secara luas untuk melihat ada atau tidaknya kesalahan pada sistem.

\section{Distribution}

Aplikasi yang telah melalui proses testing di distribusikan sesuai kebutuhan dari steakholder dan pengembangan produk yang sudah jadi agar bisa lebih baik pada pengembangab $=\mathrm{n}$ sistem berikutnya

\section{HASIL DAN PEMBAHASAN}

A. Hasil

Proses pembuatan animasi dimulai dari Modelling 3D, animation, Green Screen, Dubbing dan Rendering untuk penggabungaan animasi yang

Dalam Tahap ini pembuatan Animasi mulai dilakukan, adapun proses pembuatan animasi terdiri dari beberapa tahapan mulai dari modeling

3D, Animation, Gren Screen, Dubbing, Rendering

dan finishing dalam penggabungan animasi dan video.Animasi.

1. Moddeling 3D

Dalam hal ini pembuatan karakter Bujang menggunakan software Blender 2.79 yang kemudian moddeling tersebut akan menjadi acuan untuk membuat tubuh (body) karkter bujang ke bentuk 3D di software Blender 3D.

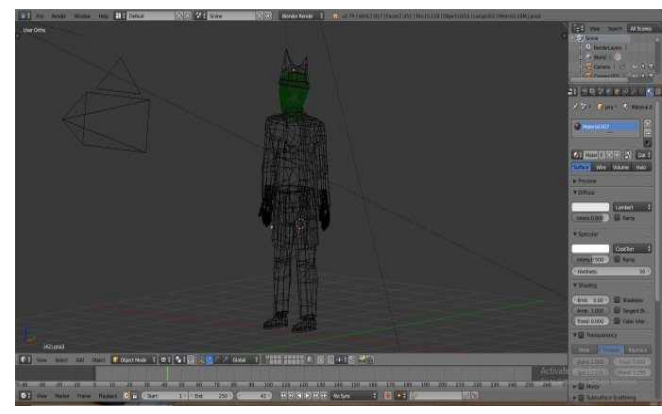

Gambar 3. Pembuatan Moddeling 3D Karakter Bujang menggunakan aplikasi Blender 2.79

\section{Pembuatan Animation}

Pembuatan Animasi diberi warna pada bagain Costum Pakaian Bujang dang Gadis, kemudian selanjutnya pemberian tekstur pada animasi Bujang dan Gadis agar membuat animasi terlihat lebih nyata, dan terakhir memberikan Pencahayaan kepada animasi sehingga warna yang dihasilkan lebih kontras dan terlihat sempurna

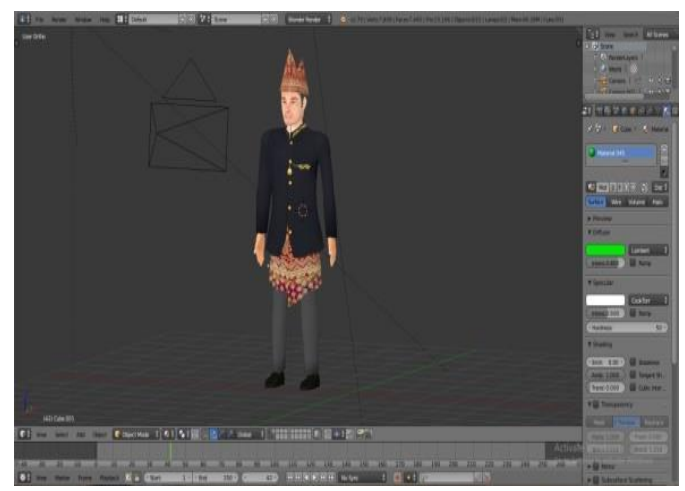

Gambar 4. Pembuatan Animasi engan memberikan Warna, Tekstur, dan Pencahayaan menggunakan 
Jurnal Pseudocode, Volume VII Nomor 2, September 2020, ISSN 2355-5920, e-ISSN 2655-1845 www.ejournal.unib.ac.id/index.php/pseudocode

\section{Green Screen}

Pada tahapan ini animasi diberi green screen agar dapat digabungkan bersama video real objek wisata seluma dengan menggunakan teknik chroma key. Pemberian green screen ini juga bertujuan untuk memperjelas objek utama dan memberi latar belakang yang belakang yang lebih menarik dengan editing dan penghilangan bagaian yang tidak kontras.

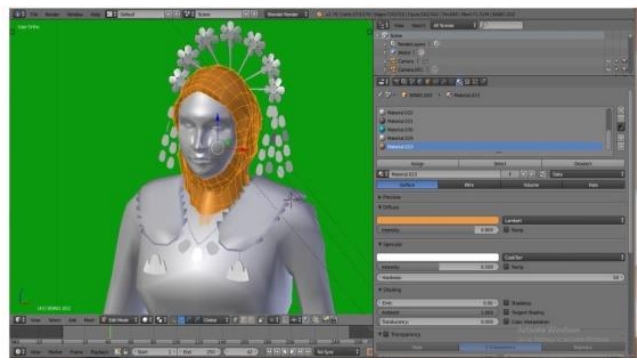

Gambar 5. Animasi bujang dan gadis Seluma diberi Green Screen

\section{Angel Camera}

Dalam proses ini Angel Camera digunakan untuk menentukan sudut pengambilan gambar animasi,dengan penentuan angel secara tepat akan menghasilkan hasil yang baik,pengambilan gambar pada animasi karakter bisa dilakukan dari sudut kiri dan kanan pada animasi karakter.

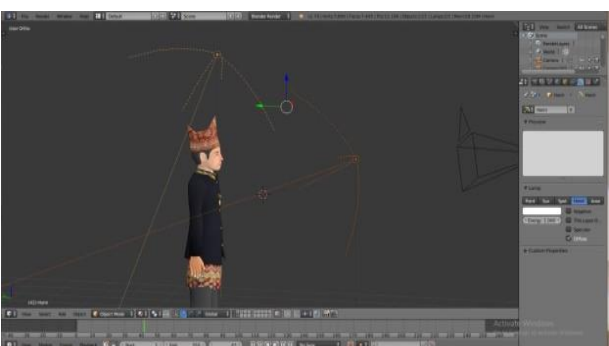

Gambar 6. Penentuan Angel pada karakter animasi.

\section{Rendering}

Proses Rendering yang bertujuan untuk pembentukan karakter animasi 3D di dalam video.

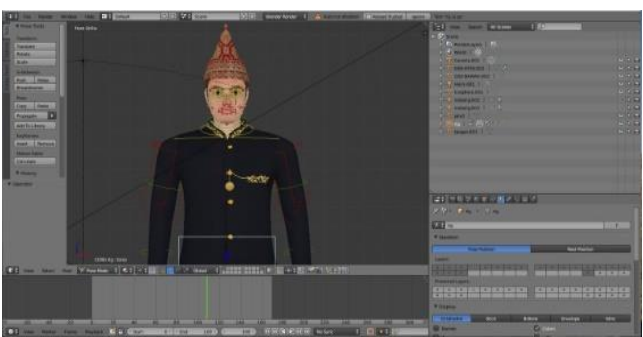

Gambar 7. Tahapan Rendering Karakter Animasi 3D.

6. Dubbing

Dalam tahapan ini Dubbing adalah proses perekaman suara yang digunakan untuk menjelaskan sesuatu secara tegas dengan suara yang jelas.

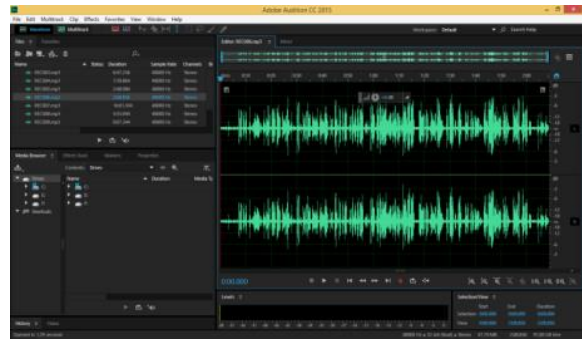

Gambar 8. Proses Dubbing Suara Animasi.

7. Editing

Tahap proses editing yaitu proses pengeditan animasi dan video menggunakan aplikasi Adobe Premiere 2019 dimana dalam proses ini akan digunakan penerapan teknik chroma key untuk menggabungkan animasi karakter 3D yang telah diberi green screen menjadi satu kedalam video real (nyata) objek wisata Seluma.

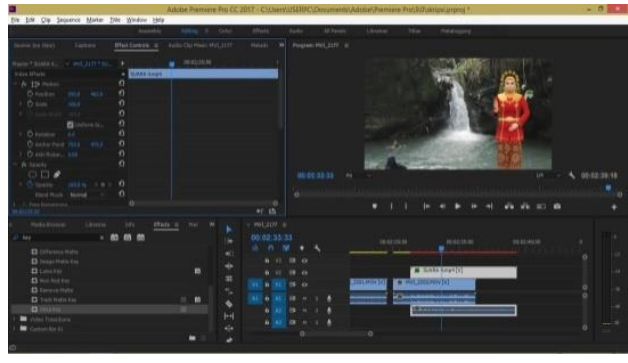

Gambar 9. Proses EditingPenggabungan animasi 3D dan video real (nyata).

\section{Penerapan Chroma Key dan Green Screen}

Penggunaan Green Screen terhadap objek utama dalam manipulasi background, dengan 
Jurnal Pseudocode, Volume VII Nomor 2, September 2020, ISSN 2355-5920, e-ISSN 2655-1845 www.ejournal.unib.ac.id/index.php/pseudocode

menghilangkan latar belakang hijua dengan video video/gambar yang lain sesuai alur cerita.
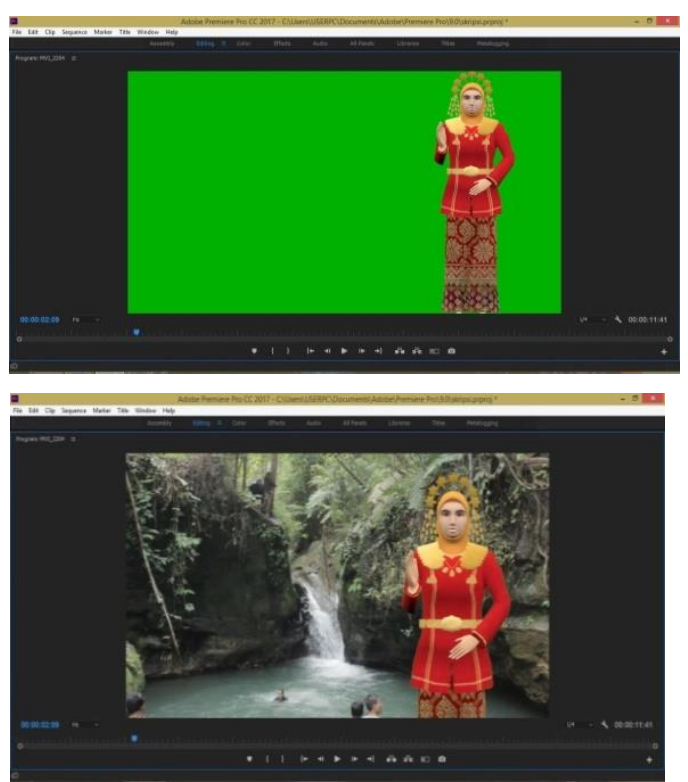

Gambar 10. Proses Penerapan teknik Chroma key dengan menggunakan green screen.

B. Pembahasan

a. Pengujian

Tahapan pengujian yang dilakukan pada animasi bujang dan gadis Seluma pengujian sebagai berikut:

\begin{tabular}{|c|c|c|c|}
\hline No & $\begin{array}{c}\text { Nama } \\
\text { Softwa } \\
\text { re }\end{array}$ & Tampilan & $\begin{array}{c}\text { Hasil } \\
\text { Pengujian }\end{array}$ \\
\hline 1 & $\begin{array}{l}\text { Gretec } \\
\text { h } \\
\text { online } \\
\text { Movie } \\
\text { (Gom) } \\
\text { Player }\end{array}$ & & $\sqrt{ }$ \\
\hline 2 & $\begin{array}{l}\text { Video } \\
\text { LAN } \\
\text { Client } \\
\text { (VLC } \\
\text { Player }\end{array}$ & $f$ & $\sqrt{ }$ \\
\hline 3 & $\begin{array}{l}\text { Windo } \\
\text { ws } \\
\text { Media } \\
\text { Player }\end{array}$ & & $\sqrt{ }$ \\
\hline
\end{tabular}

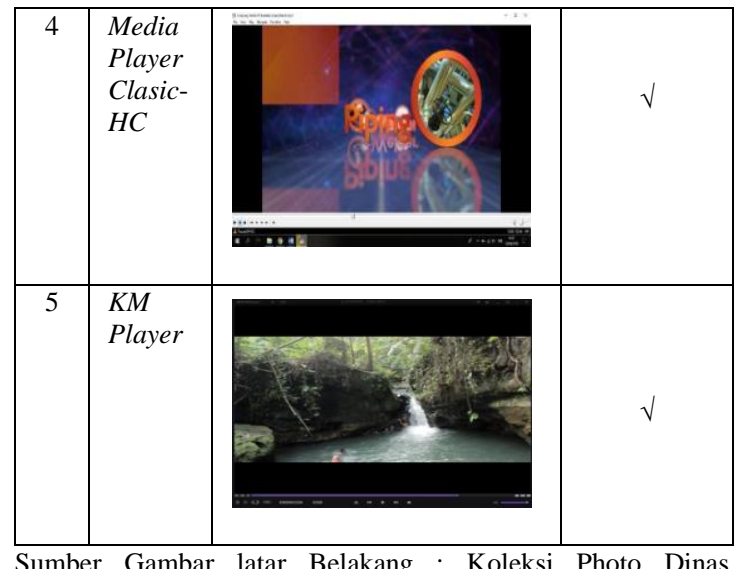

Sumber Gambar latar Belakang : Koleksi Photo Dinas Pariwisata Kabupaten Seluma.

b. Hasil Pengujian

1. Tidak berat saat melakukan render, mudah untuk digunakan dan Tidak membutuhkan ruang kapastias yang banyak dan memilki antarmuka yang memanjakan mata, serta memudahkan untuk mengoperasikan proses editing video karena memilki tampilan serta preview yang membuat editing video menjadi lebih mudah.

2. Bisa diputar dengan berbagai macam jenis aplikasi media player.

3. Dapat menambahkan fitur efek-efek khusus seperti efek cahaya, bayangan, kabut dan lain-lain, dapat menjalankan proses animasi sesuai keingan pengguna

4. Membutuhkan spesifikasi komputer yang berada pada rentang medium sampai highend dan Semua proses dilakukan dengan manual

\section{KESIMPULAN}

Berdasarkan hasil pengujian yang telah dilakukam dapat disimpulkan sebagai berikut:

1. Mudah dalam inflemantasikannya karena tidak membutuhkan penyimpanan yang besar dan bisa diputar dihampir semua media player serta memilki tampilan yang menarik. 
Jurnal Pseudocode, Volume VII Nomor 2, September 2020, ISSN 2355-5920, e-ISSN 2655-1845 www.ejournal.unib.ac.id/index.php/pseudocode

2. Pengguna dapat menambah sendiri fitur-fitur animasi yang dibutuhkan dengan memberi efe-efek untuk membuat gambar lebih menarik.

3. Kelemahan dari dari penggunaan Adobe Premiere adalah kebutuhan spesifikasi komputer yang lebih tinggi atau high-end.

\section{REFERENSI}

[1] Ilham Eka Putra, Wahyudi. 2015. Rancang Bangun APlikasi Promosi Pariwisata Berbasis Multimedia Interaktif Kabupaten Pesisir Selatan Sumatera Barat. Jurnal TEKNOIF.

[2] Arin Yuli Astuti, dkk. (2016). Optimalisasi Editing green screen menggunakan teknik lighting pada CHROMA KEY. Jurnal ilmiah multitek indonesia, Vol 10 No. 1, ISSN : 1907-6223

[3] Suwasono, A. A. (2016). PENGANTAR ANIMASI 2D Metode Dasar Perancangan Animasi Tradisional

[4] Jodi Rinaldi, Rumagit, A.M, dkk. (2012). Perancangan Tutorial penerimaan Mahasiswa Baru Universitas Sam Ratulangi Berbasis Animasi 3D.Jurnal TeknikElektro-FT UNSRAT, 1 - 6.

[5] Miranti e Awulle, dkk. 2016. Pembuatan film animasi 3d menggunakan metode dynamic simulation (studi kasus: Alramona N'Taumatta N'Talroda). Jurnal Teknik Elektro dan Komputer. Vol 5 No,4

[6] Sihite, B., Samopa, F., \& Sani, N. A. (2013). Pembuatan Aplikasi 3D Viewer Mobile dengan Menggunakan Teknologi Virtual Reality (Studi Kasus: Perobekan Bendera Belanda di Hotel Majapahit). Jurnal Teknik ITS, 2(2), A397-A400.

[7] Fauzi, M. (2019). Penggunaan tekhnik blueprint pada pemodelan objek 3d. JTIK (Jurnal Teknik Informatika Kaputama), 3(1), 35-41.

[8] Pradhana, F. R., Karaman, J., \& Andriyanto, S. (2016). Optimalisasi Penggunaan Efek Chroma Key Pada Video dengan Menggunakan Metode Dual Layer Green Screen. SEMNASTEKNOMEDIA ONLINE, 4(1), 4-8.

[9] Triadiputra, S. A., \& Waskito, S. B. (2019). GAMBAR PITUTUR PUNAKAWAN SEBAGAI INSPIRASI PENCIPTAAN VIDEO KANAL TUNGGAL.

[10] Loury hadasa armanto. 2017. implementasi unsur live shot dan special effect dalam film karakter yang tidak dipeduli lingkungan .tugas akhir.batam.

[11] Kusumo, F., \& Sulartopo, S. (2019). Perancangan Video Company Profile Sebagai Media Promosi dan Informasi Pada Toko Citra Meubel Semarang. Pixel: Jurnal Ilmiah Komputer Grafis, 12(1), 33-41.

[12] Busyaeri, A., Udin, T., \& Zaenudin, A. (2016). Pengaruh penggunaan video pembelajaran terhadap peningkatan hasil belajar mapel IPA di MIN Kroya Cirebon. Al Ibtida: Jurnal Pendidikan Guru MI, 3(1).
[13] Rabbi Radliya, N. (2016). Bab 1-Sejarah Animasi

[14] DIMENSI SEBAGAI MEDIA SOSIALISASI PENCEGAHAN PELECEHAN SEKSUAL TERHADAP ANAK. KARMAPATI (Kumpulan Artikel Mahasiswa Pendidikan Teknik Informatika), 5(2), 105119.

[15] Farraseka, I. D. (2020). LKP: Editor dalam Pembuatan Video di PT. Koen Cinema Indonesia (Doctoral dissertation, Universitas Dinamika).

[16] .Rachmanto, A. D. (2019). Implementasi Augmented Reality Sebagai Media Pengenalan Promosi Universitas Nurtanio Bandung Menggunakan Unity 3D. Jurnal Teknologi Informasi dan Komunikasi, 8(1).

[17] Khulsum, U., Hudiyono, Y., \& Sulistyowati, E. D. (2018). Pengembangan Bahan Ajar Menulis Cerpen dengan Media Storyboard pada Siswa Kelas X SMA. Diglosia: Jurnal Kajian Bahasa, Sastra, dan Pengajarannya, 1(1), 1-12.

[18] Punusingon, R. R., Lumenta, A. S., \& Rindengan, Y. D. Y. (2017). Animasi Sosialisasi Undang-Undang Informasi dan Transaksi Elektronik. Jurnal Teknik Informatika, 12(1).

[19] Sunarya, L., Saputra, H. S., \& Rahmadhiani, D. (2017). Perancangan Video Profile pada Smk Islamic Village Karawaci Kabupaten Tangerang. Journal Sensi, 3(2), 160-172.

[20] Dewantoro, B. M. (2013). Tutorial Beladiri Taekwondo Berbasis 3D Menggunakan Blender (Doctoral dissertation, Universitas Muhammadiyah Surakarta)

[21] Harahap, E. P., Rahardja, U., \& Salamuddin, M. (2019). Aplikasi Panduan dan Pembayaran Tiket Masuk Mendaki Gunung Menggunakan Metodologi Sistem Multimedia Luther-Sutopo. Sains dan Teknologi Informasi, 4(2), 9-16. 